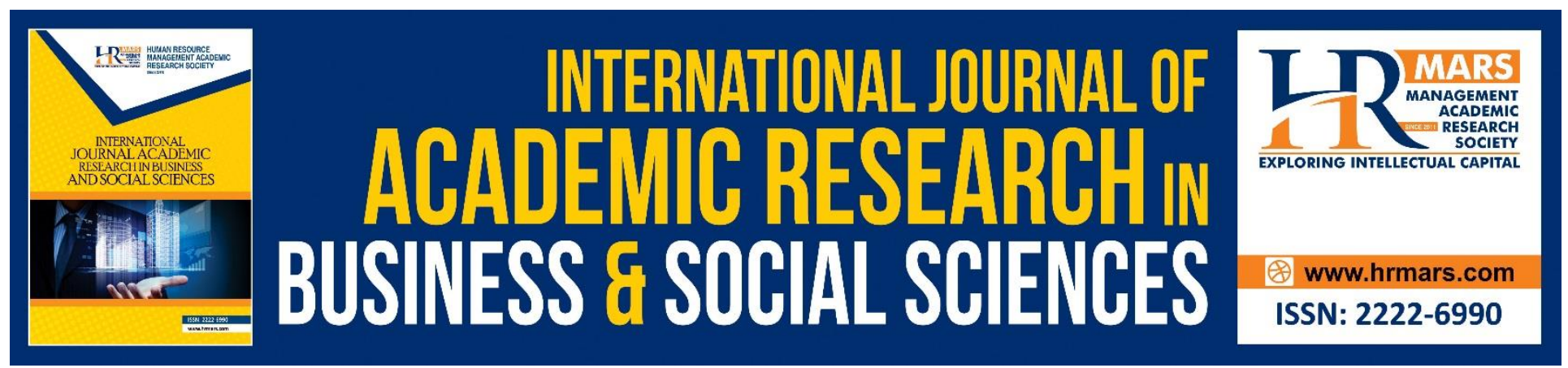

\title{
Workers Survived from Commuting Road Crashes: Who are they?
}

Nurrul Hafeezah Sahak, Kulanthayan K.C Mani, Titi Rahmawati Hamedon,
Krishna Gopal Rampal and Kathirkamanathan Vythialingam

To Link this Article: http://dx.doi.org/10.6007/IJARBSS/v10-i15/8342

DOI:10.6007/IJARBSS/v10-i15/8342

Received: 20 October 2020, Revised: 13 November 2020, Accepted: 30 November 2020

Published Online: 24 December 2020

In-Text Citation: (Sahak et. al., 2020)

To Cite this Article: Sahak, N. H., Mani, K. K. C., Hamedon, T. R., Rampal, K. G., and Vythialingam, K. (2020). Workers Survived from Commuting Road Crashes: Who are they? International Journal of Academic Research in Business and Social Sciences. 10(15), 359-367.

\section{Copyright: () 2020 The Author(s)}

Published by Human Resource Management Academic Research Society (www.hrmars.com)

This article is published under the Creative Commons Attribution (CC BY 4.0) license. Anyone may reproduce, distribute, translate and create derivative works of this article (for both commercial and non-commercial purposes), subject to full attribution to the original publication and authors. The full terms of this license may be seen at: http://creativecommons.org/licences/by/4.0/legalcode

Special Issue: Youth and Community Wellbeing: Issues, Challenges and Opportunities for Empowerment V1, 2020, Pg. 359 - 367

Full Terms \& Conditions of access and use can be found at http://hrmars.com/index.php/pages/detail/publication-ethics 


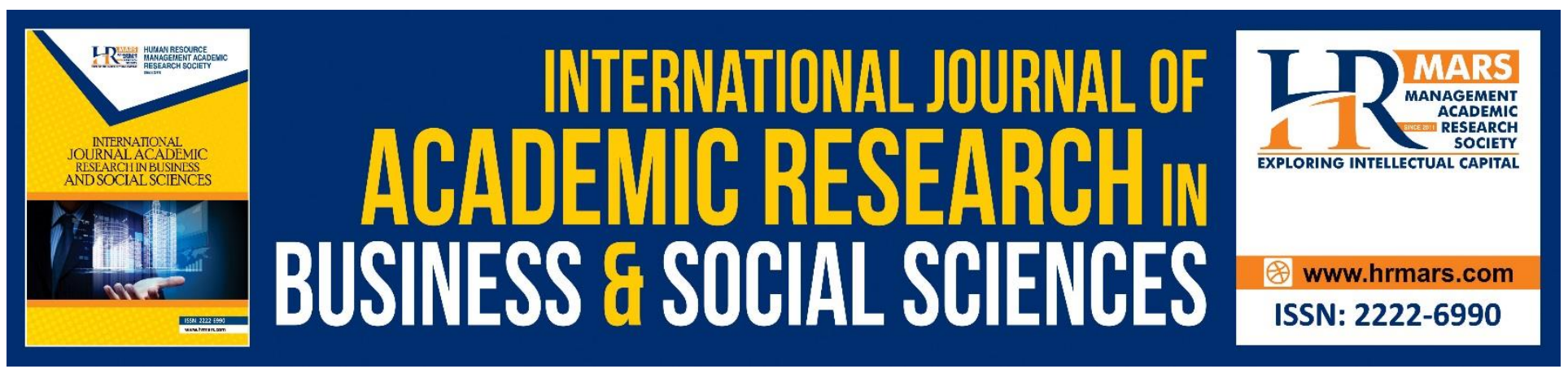

\title{
Workers Survived from Commuting Road Crashes: Who are they?
}

\author{
Nurrul Hafeezah Sahak ${ }^{1}$, Kulanthayan K.C Mani', Titi Rahmawati \\ Hamedon ${ }^{1}$, Krishna Gopal Rampal ${ }^{2}$ and Kathirkamanathan \\ Vythialingam ${ }^{3}$ \\ ${ }^{1}$ Department of Community Health, Faculty of Medicine and Health Sciences, Universiti Putra \\ Malaysia, 43400 Serdang, Malaysia, ${ }^{2}$ Cyberjaya University College of Medical Sciences, 63000 \\ Cyberjaya, Malaysia, ${ }^{3}$ School of Occupational Therapy, Perdana University, 43400 Serdang, \\ Malaysia \\ Email: kulan@upm.edu.my
}

\begin{abstract}
Background: Commuting road crashes are road traffic crashes that involve workers while travelling in the course of work. The more worker travels, the higher the probability of the occurrence of commuting road crashes. The aim of this study was to determine baseline sociodemographic, employment and injury and characteristics of injured workers who survived from commuting road crash. Methods: Eligible 200 workers who were involved in commuting road crash were identified and invited to be part of this study. Sociodemographic, employment and injury-related questions were distributed to identified and consented injured workers. Results: Majority (79.5\%) of the respondents were aged 25 years old or older, male (86.0\%), married or divorced (63.5\%), and attained secondary and below education level (66.0\%). Most of the injured workers consisted of blue-collar workers (69\%), had fracture injury (93.0\%), and had injury to their lower limbs (48.5\%). A higher percentage (63.5\%) of injured workers had returned to work compared to those who were still not working (36.5\%) after involved in commuting road crash. Conclusion: Commuting road crashes are common to blue collar workers as they are more prone to use motorcycles to commute due to cheaper price compare to other type of transportation such as car.
\end{abstract}

Keywords: Commuting Road Crash, Road Traffic Injuries, Blue Collar Workers, Workers Survived, Malaysia.

\section{Introduction}

Workers depend on road transportation for easy access to the workplace and vice versa. However, with the increasing number of vehicles on the road, especially during peak hours when workers commute, the risk of being involved in a road traffic crash (RTC) is also increasing. 
Commuting road crashes are part of RTC that involve workers. According to past literature on commuting road crashes from different countries of the world like Finland (Nenonen, 2013), Austria (Halla et. al, 2013) and Saudi Arabia (Elshinnawey et. al, 2008) it can be summarized that commuting road crashes are RTCs that cause injuries to workers due to the course of work while travelling in either direction between work or a work-related training place, and workers residence, place where workers usually take their meals or place where workers usually receive their remuneration.

Data from Social Security Organization (SOCSO) indicated that $89.3 \%$ of Malaysian commute to work using own vehicles. Only $8.7 \%$ commute using transportation provided by employer and $1.9 \%$ take public transport. Majority (68.8\%) of workers who involved in commuting road crash were on morning shift and $52.1 \%$ of injured workers involved in crash during commuting to work.

Commuting road crashes cause economic losses to injured workers, their families as well as to the country. During long absenteeism from employment due to commuting road crashes, those injured workers do not receive full monthly income salary from their respective employers. Although the injured workers receive approximately $80 \%$ of their average daily income from the SOCSO temporary disablement benefit during their medical leave, the amount is not enough for their expenses in order to maintain their pre-injury lifestyle, especially for those who are the breadwinner of the family. Work-related disablement of household heads is proven to cause major economic hardship for families due to the loss of earnings (Hyder, 2004; Geziary et. al, 2004).

Economic losses may also arise from the cost of treatment and labour lost. In more serious cases, family members need to take time off work to care for the injured workers during the treatment or recovery period as injured workers struggle to take care of themselves at home (Franze, 2006) due to pain and the functional limitations for self-management. Disability due to commuting road crashes affect all ages but the most affected are those in the young and productive years of their life.

According to the World Health Organization (WHO), RTCs cost most countries 3\% of their gross domestic product (GDP). In 2016, RTCs cost Malaysia an estimated RM 9.21 billion. Malaysian Institute of Road Safety Research (MIROS) estimates that death due to RTC cause the country an average of RM 1.2 million, RM120,000 for severe injury and RM 12,000 for light injury in medical cost, productivity loss and other pay-outs.

Commuting road crashes may also have implications such as a limitation in the social activities of the injured workers due to physical pain or low self-esteem. As a result, psychological consequences like depression, anxiety or stress may arise among these commuting road crash victims and their family members. This may lead to a reduction in the quality of life of the injured workers (Baranyi et. al, 2010).

In different countries, the return to work (RTW) rates among injured workers differ, which might be due to the different definitions of RTW, different types of work-related injuries or the time of RTW rate being calculated (example 6- or 12-months post-injury). In China, a retrospective cohort study on work-related injury reported that $92.9 \%$ of injured workers in the study on RTW had resumed 
work at the seven months follow-up (He et. al, 2010). Lower RTW rates, ranging between 65 and $72 \%$, were found in French RTW-related studies (Poulain et. al, 2010). Generally, according to a review article, RTW rates for 71 worldwide studies ranged between $29 \%$ and $100 \%$ with a median rate of 67\% (Athanasou, 2005).

On top of this, the differences in the RTW rates are also due to the different types of rehabilitation received by injured workers. Researchers (Al-Dawood, 2000; Hyder, 2004; Khorasani-Zavareh, 2009) reported and believed that effective rehabilitation is able to minimize the physical consequences of commuting road crashes so that injured workers are able to get RTW as soon as possible after being involved in a commuting road crash.

In Malaysia, SOCSO was appointed as the government statutory body to provide protection for workers who suffer from accidents arising from work including commuting road crashes. The coverage of protection for this kind of injury is provided under the Employment Injury Insurance Scheme, one of the benefits under this scheme is rehabilitation and its RTW Program is part of the rehabilitation. SOCSO has taken the initiative to provide multidisciplinary rehabilitation (physical and vocational rehabilitation) to the injured insured workers in order to enhance their productivity and efficiency after being involved in work-related accidents.

\section{Methods}

\section{Study Design}

This was a randomized controlled trial study with allocation concealment. This study was part from a bigger study on the effectiveness of self-management intervention among commuting crash survivors. Participants who consented to be in the study were originated from Social Security Organization (SOCSO) RTW Program.

\section{Participants}

To be eligible for this study, potential participants were selected based on the inclusion criteria, i.e., vehicle driver, passenger, motorcyclist, cyclist or pedestrian, involved in a commuting crash, newly reported case (within the year 2014/2015), and there was no plan for RTW within the next month.

\section{Exclusion Criteria}

A worker will not be chosen based on the exclusion criteria - had sick leave for longer than 52 weeks

\section{Recruitment}

The principal investigator assessed the eligibility of respondents who had agreed to participate in the SOCSO RTW programme. Participants were identified by the researcher with the referral from the SOCSO case managers. Case managers are the person-in-charge of each RTW case, right from the identification of eligible injured workers to participate in the RTW programme up to the six months' follow-up after they have returned to the labour market. The role of the case manager is to manage each case of employment injury, give full support to the RTW programme participant, and identify suitable rehabilitation services to facilitate them to return to work. The case manager is also responsible for mediating the link between all the parties involved in the RTW programme 
(employee, employer, family member, and health professionals) to ensure the success of the RTW. Informed written consent was obtained from the study participants after the purpose and nature of the procedure had been fully explained to them.

\section{Instrumentation}

Participants were required to answer a set of questionnaires - sociodemographic, employment and injury-related questions. Sociodemographic section comprised of questions to identify injured workers' information, such as age, gender, marital status and highest education level. Employmentrelated questions were on type of job (blue-collar or white-collar) and monthly income. Injured workers' injury-related section was more focused on the nature of injury as well as location of injury to body parts.

Data analysis

The descriptive statistics were the mean (standard deviation) or number (percentage). All analyses were performed using SPSS software version 20.0 .

\section{Results}

Response rate

A total of 209 injured workers were approached during the recruitment period to assess their eligibility for participating in the study. From that figure, nine persons were excluded because they did not meet the inclusion criteria (five persons) or declined to participate (four persons).

Injured workers' sociodemographic characteristics

Table 1 shows the distribution of the sociodemographic characteristics of the respondents. The overall mean age of 200 participants was 32.3 years $(S D= \pm 8.2)$. The majority $(79.5 \%)$ of the respondents were aged 25 years old or older, male (86.0\%), married or divorced (63.5\%), and attained secondary and below education level (66.0\%).

Table 1: Injured workers' sociodemographic characteristics

\begin{tabular}{lcc}
\hline \multicolumn{1}{c}{ Respondents characteristics } & Frequency N (\%) & Mean \pm SD \\
\hline Age (year) & $41(20.5)$ & $32.3 \pm 8.2$ \\
$\leq 24$ & $159(79.5)$ & \\
$\geq 25$ & & \\
Gender & $172(86.0)$ & \\
Male & $28(14.0)$ \\
Female & & \\
Marital status & $73(36.5)$ \\
Single & $127(63.5)$ \\
Married/ divorced & $132(66.0)$ \\
Highest education level & $68(34.0)$ \\
Secondary education and below &
\end{tabular}


Injured workers' employment and injury characteristics

Table 2 shows the distribution of the employment and injury characteristics of the respondents. The majority (69.0\%) of the respondents consisted of blue-collar workers, had fracture injury (93.0\%), and had injury to their lower limbs (48.5\%). The overall mean monthly income received by the respondents in this study was $\mathrm{RM} 2232.8$ (SD= $\pm \mathrm{RM} 1079.2)$.

Table 2: Injured workers' employment and injury characteristics

\begin{tabular}{lcc}
\hline \multicolumn{1}{c}{ Respondents characteristics } & Total N (\%) & Mean \pm SD \\
\hline Occupation category & $138(69.0)$ & \\
Blue-collar workers & $62(31.0)$ & $2232.8 \pm 1079.2$ \\
White-collar workers & & \\
Monthly income (RM) & $138(69.0)$ & \\
$\leq 2312$ & $62(31.0)$ \\
$\geq 2313$ & & \\
Nature of injury & $186(93.0)$ \\
Fracture & $11(5.5)$ \\
Tear & $3(1.5)$ \\
Dislocation & \\
Location of injury & $1(0.5)$ \\
Neck & $4(2.0)$ \\
Trunk & $67(33.5)$ \\
Upper limb & $97(48.5)$ \\
Lower limb & $31(15.5)$ \\
Multiple injuries & \\
\hline
\end{tabular}

Return to Work (RTW) rate

The work status of the injured workers was categorised as either RTW or not RTW. A higher percentage $(63.5 \%)$ of injured workers had returned to work compared to those who were still not working $(36.5 \%)$ after involved in commuting road crash.

Table 3: Work status rate

\begin{tabular}{cc}
\hline Work status & Frequency \\
\hline RTW & $125(63.5 \%)$ \\
Not RTW & $72(36.5 \%)$ \\
\hline
\end{tabular}

\section{Discussion}

This study's findings recorded that the highest percentage of study participants involved in the commuting road crashes were aged 25 years old or older. This study's finding was similar to previous study (Oxley, 2013) as both studies were conducted among workers who were involved in commuting road crashes in Malaysia for different time periods. 
Males recorded the highest percentage of participants in this study compared to their counterparts and this finding was in agreement with the current RTC scenario in Malaysia, as commuting road crashes are also part of RTCs. Interestingly, past studies (Charbotel et. al, 2010; Christie et. al (2016) also agreed that more male workers than female workers were involved in work-related accidents.

This study's findings are similar to other study (Prang et.al, 2015) in terms of being married and the likelihood of being involved in commuting road crashes. The education level in this study was classified into two categories, and the findings showed that most of the injured workers had secondary or lower education level. Those with lower educational level have a higher risk of being involved in RTCs as they tend to disobey traffic safety rules, such as not wearing safety helmets in a proper way and speeding (Alicioglu et. al, 2008).

The pre-injury employment information of injured workers in this study was classified into blue-collar and white-collar jobs. The blue-collar jobs or more physically demanding job tasks were the most common type of pre-injury employment among the injured workers in both the intervention and the control group. For this study, most of the blue-collar workers worked as dispatch riders or postmen, which required them to travel as part of the nature of their job. All the injured workers in this study were using a motorcycle at the time of the crash. Thus, this group of workers had a higher risk of getting involved in commuting road crashes compared to workers who spend most of their working hours in the office.

According to the Malaysia Department of Statistics, the mean monthly income among Malaysian workers in 2015 was RM 2312. Therefore, this study indicated that the majority of the injured workers received a monthly income that was below the country's mean monthly income. Low socioeconomic status of an individual could increase their risk of being involved in an RTC as they are more prone to use motorcycles to commute to work (Alicioglu et. al, 2008). This could be because motorcycles are a relatively cheap option for transportation and for dealing with traffic congestion. Therefore, this could be the reason why all the injured workers in this study were involved in commuting road crashes due to motorcycle (two-wheeler) which is a risky vehicle compare to car or public transport (four-wheel).

This current study had similar findings to other studies (Alicioglu et. al, 2008; Bayan et. al, 2013) where motorcycle crashes caused the highest percentage of injury to lower limbs. The reason for this was due to the gravitational force and velocity of the motorcycle at the time of the commuting road crash (Singh et.al 2014).

Prolonged absenteeism as a result of commuting road crashes is a major problem as it has a domino effect that not only affects the injured worker who is off work, but also other related parties in terms of the economy, mental health, and HRQOL. Therefore, getting RTW as soon as possible is crucial to curb this problem before it gets worse, as according to the rule of thumb for RTW, the longer a person remains off work, the higher the risk of ongoing work disability (Poulain et. al, 2010) and the greater the chances of permanent disability (Lambeek et. al, 2010) which may lower the probability of getting RTW (Hepp et. al, 2011; Reme et. al, 2009). 


\section{Conclusions}

Workers who work as blue-collar workers had low socioeconomic status, as their monthly income was lower than the country's mean monthly income. They opted for a cheaper mode of transportation, which is the motorcycle for commuting. Thus, this increased their risk of getting involved in commuting road crashes.

\section{Recommendation}

In future, follow-up studies should be conducted between those who had RTW and not RTW. This assessment is important to determine the long-term effect of commuting road crash between those who had RTW and not RTW group.

Wherever possible, future studies should implement early intervention to have a more positive impact on the workers who RTW. Relevant authorities should collaborate with hospitals to identify injured workers who have a potential delay to RTW due to their injury. Providing early intervention to injured workers might help them recover faster and assist them in returning to employment without further disability.

\section{Acknowledgments}

This research was supported via seed funding from the Social Security Organization (SOCSO), Malaysia.

\section{References}

Alicioglu, B., Yalniz, E., Eskin, D., \& Yilmaz, B. (2008). Injuries associated with motorcycle accidents. Acta Orthopaedica et Traumatologica Turcica, 42(2): 106-111.

Al-Dawood, K. M. (2000). Direct impact of non-fatal occupational injuries. Saudi Medical Journal, 21(10): 938-41.

Athanasou, J. A. (2005). Return to work following whiplash and back injury: a review and evaluation. Medico-Legal Journal, 73(1): 29-33.

Baranyi, A., Leithgob, O., Kreiner, B., Tanzer, K., Ehrlich, G., Hofer, H. P., \& Rothenhausler, H.-B. (2010). Relationship between posttraumatic stress disorder, quality of life, social support, and affective and dissociative status in severely injured accident victims 12 months after trauma. Psychosomatics, 51: 237-247.

Bayan, P., Bhawalkar, J. S., Jadhav, S. L., \& Banerjee, A. (2013). Profile of non-fatal injuries due to road traffic accidents from a industrial town in India. International Journal of Critical IIIness and Injury Science, 3(1): 8-11.

Charbotel, B., Martin, J. L., \& Chiron, M. (2010). Work-related versus non-work-related road accidents, developments in the last decade in France. Accident Analysis and Prevention, 42(2): 604-611.

Christie, N., Beckett, K., Earthy, S., Kellezi, B., Sleney, J., Barnes, J., \& Kendrick, D. (2016). Seeking support after hospitalisation for injury: A nested qualitative study of the role of primary care. British Journal of General Practice, 66(642): e24-e31. 
Elshinnawey, M. A., Fiala, L. E., Abbas, M. A., \& Othman, N. (2008). Road traffic injuries in saudi arabia, and its impact on the working population. The Journal of the Egyptian Public Health Association, 83(1-2): 1-14.

Franze, C., Bjonstig, U., \& Jansson, L. (2006). Injured in traffic : Experiences of care and rehabilitation. Accident and Emergency Nursing, 14: 104-110.

Geziary, H. A., El Sayed, H., Hussain, S. J., \& Sakr, H. I. (2004). Road safety: the potholes of neglect. East Mediterr Health J, 10(3): 252-259.

Halla, M., \& Zweimüller, M. (2013). The effect of health on earnings: Quasi-experimental evidence from commuting accidents. Labour Economics, 24: 23-38.

He, Y., Hu, J., Yu, I. T. S., Gu, W., \& Liang, Y. (2010). Determinants of return to work after occupational injury. Journal of Occupational Rehabilitation, 20(3): 378-386.

Hepp, U., Moergeli, H., Buchi, S., Bruchhaus-Steinert, H., Sensky, T., \& Schnyder, U. (2011). The longterm prediction of return to work following serious accidental injuries: a follow up study. BMC Psychiatry, 11(1): 53.

Hyder, A. A. (2004). Road safety is no accident: a call for global action. Bulletin of the World Health Organization, 82(4): 240.

Khorasani-Zavareh, D., Khankeh, H. R., Mohammadi, R., Laflamme, L., Bikmoradi, A., \& Haglund, B. J. a. (2009). Post-crash management of road traffic injury victims in Iran. Stakeholders' views on current barriers and potential facilitators. BMC Emergency Medicine, 9(8).

Lambeek, L. C., van Mechelen, W., Knol, D. L., Loisel, P., \& Anema, J. R. (2010). Randomised controlled trial of integrated care to reduce disability from chronic low back pain in working and private life. BMJ, 340: c1035-c1035.

Nenonen, N. (2013). Analysing factors related to slipping, stumbling, and falling accidents at work: Application of data mining methods to Finnish occupational accidents and diseases statistics database. Applied Ergonomics, 44(2): 215-224.

Oxley, J., Yuen, J., Ravi, M. D., Hoareau, E., Mohammed, A., \& Bakar, H. (2013). Commuter motorcycle crashes in Malaysia : An understanding of contributing factors. Annals of Advances in Automative Medicine, 57: 45-54.

Poulain, C., Kernéis, S., Rozenberg, S., Fautrel, B., Bourgeois, P., \& Foltz, V. (2010). Long-term return to work after a functional restoration program for chronic low-back pain patients: A prospective study. European Spine Journal, 19(7): 1153-1161.

Prang, K.-H., Berecki-Gisolf, J., \& Newnam, S. (2015). Recovery from musculoskeletal injury: the role of social support following a transport accident. Health and Quality of Life Outcomes, 13: 97.

Reme, S. E., Hagen, E. M., \& Eriksen, H. R. (2009). Expectations, perceptions, and physiotherapy predict prolonged sick leave in subacute low back pain. BMC Musculoskeletal Disorders, 10: 139.

Singh, R., Singh, H. K., Gupta, S. C., \& Kumar, Y. (2014). Pattern, severity and circumtances of injuries sustained in road traffic accidents: a tertiary care hospital-based study. Indian Journal of Community Medicine, 39(1): 30-4. 